\title{
Luminescence Nanoprobe in the Near-Infrared-II Window for Ultrasensitive Detection of Hypochlorite
}

Xiao Fu, ${ }^{a}$ Jinmei $W u,{ }^{a}$ Huajian Xu $,{ }^{a}, *$ Pingping Wan, ${ }^{a}$ Huimin Fu, ${ }^{a}$ and Qingsong $M e i^{b, *}$

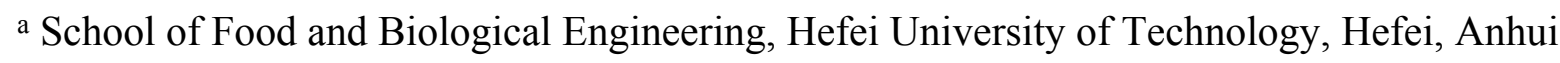
230009, China. E-mail: hjxu@hfut.edu.cn

b School of Medicine, Jinan University, Guangzhou, Guangdong 510632, China. E-mail:

qsmei@jnu.edu.cn 


\section{Table of contents}

Figure S1. Luminescence comparison between two different nanoparticles.

Figure S2. TEM images and particle size distributions.

Figure S3. High-resolution TEM image.

Figure S4. TEM images and size distributions in the length and width directions of the core and core-shell nanoparticles.

Figure S5. XRD patterns of the core and core-shell nanocrystals.

Figure S6. Log-log plots of the emission intensity towards power density.

Figure S7. Down-converted emission spectra of oleic acid capped DCNPs.

Figure S8. The absorption spectral of the dye FD1080.

Figure S9. Photo of FD1080 before and after reacting with hypochlorite. Luminescence decay curves of $\mathrm{Yb}$ ions at $980 \mathrm{~nm}$.

Figure S10. The luminescence quenching comparison of different nanoparticles.

Figure S11. Mass spectra of FD1080 before and after reacting with hypochlorite.

Figure S12. Down-convert emission spectra of the mDCNPs and FD1080. The luminescence quenching of FD1080 after additions of different amounts of hypochlorite.

Figure S13. The influence of $\mathrm{pH}$ values on the luminescence enhancement.

Figure S14. Raw milk samples for hypochlorite detection.

Table S1. An overview of recent literatures of hypochlorite detections. 


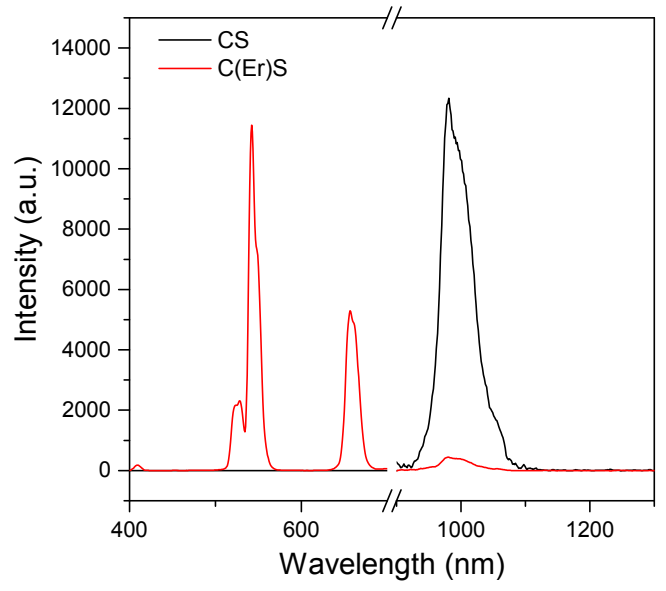

Figure S1. Luminescence comparison between the nanoparticles $\mathrm{NaYF}_{4}: \mathrm{Yb}$ (90\%)@NaNdF $: \mathrm{Yb}$ (black line) and $\mathrm{NaYF}_{4}: \mathrm{Yb} / \mathrm{Er}(90 \% / 2 \%) @ \mathrm{NaNdF}_{4}: \mathrm{Yb}$ (red line) upon excitation with $808 \mathrm{~nm}$. 

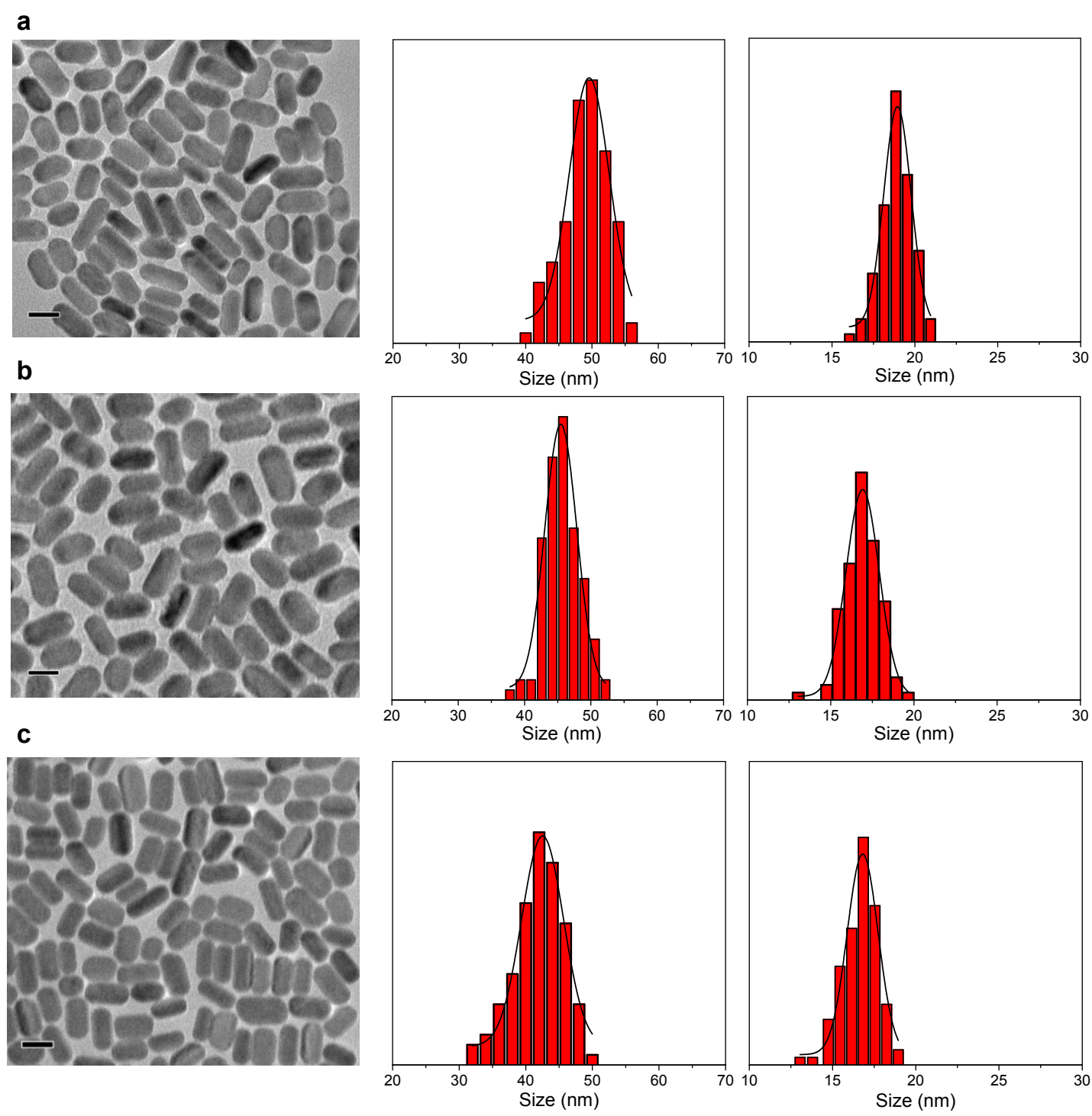

Figure S2. TEM images and particle size distributions in width direction (middle panel) and length direction (right panel) of the nanoparticles $\mathrm{NaYF}_{4}: \mathrm{x} \% \mathrm{Yb} @ \mathrm{NaNdF}_{4}: \mathrm{Yb}$. (a-c) The doping amounts of $\mathrm{Yb}$ ion in core nanoparticles were 10\%, 30\% and 50\%, respectively. Scale bars are $50 \mathrm{~nm}$. 


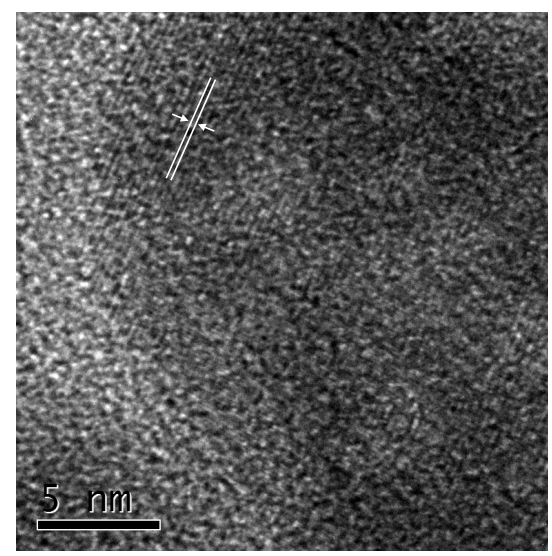

Figure S3. High-resolution TEM image of the core-shell nanoparticle, $\mathrm{NaYF}_{4}: 90 \% \mathrm{Yb} @ \mathrm{NaNdF}_{4}: \mathrm{Yb}$.
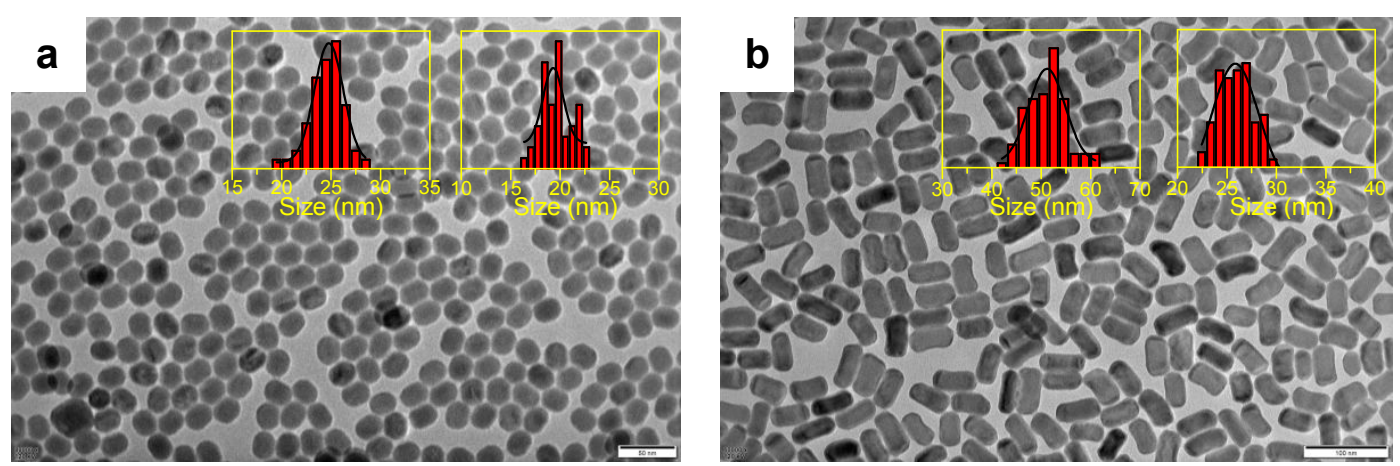

Figure S4. TEM images and size distributions in the length (left) and width (right) directions of the core (a) and core-shell (b) nanoparticles. 


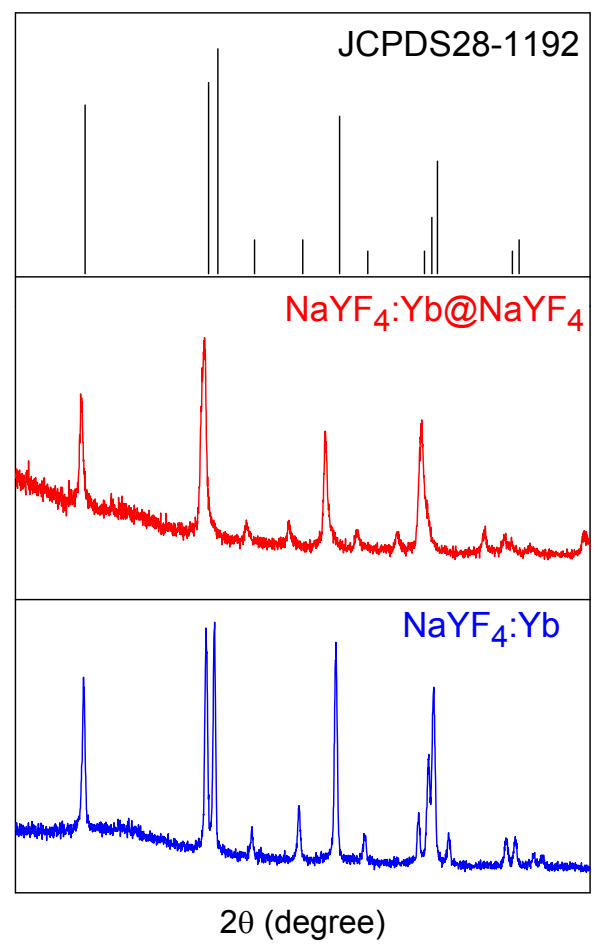

Figure S5. XRD patterns of the core nanocrystals $\mathrm{NaYF}_{4}: \mathrm{Yb}(90 \%)$, and core-shell nanocrystals $\mathrm{NaYF}_{4}: \mathrm{Yb}(90 \%) @ \mathrm{NaYF}_{4}$.

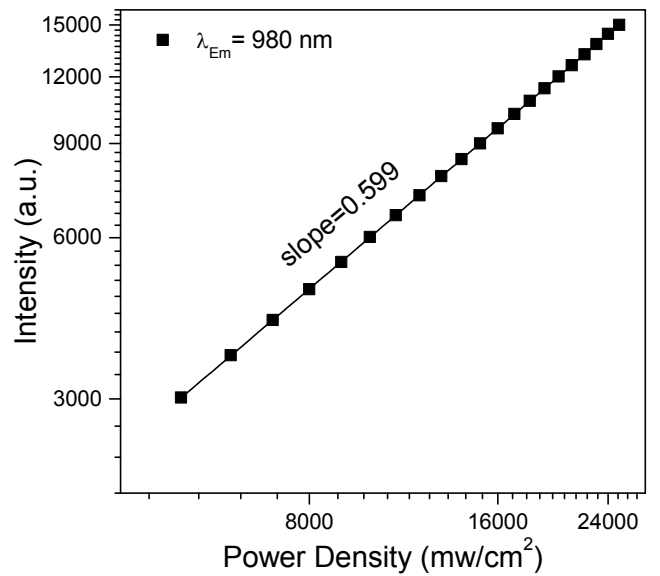

Figure S6. Log-log plots of the emission at $980 \mathrm{~nm}$ of the DCNPs, $\mathrm{NaYF}_{4}: 90 \% \mathrm{Yb} @ \mathrm{NaNdF}_{4}: \mathrm{Yb}$, toward the power density of $808 \mathrm{~nm}$ lasers. 

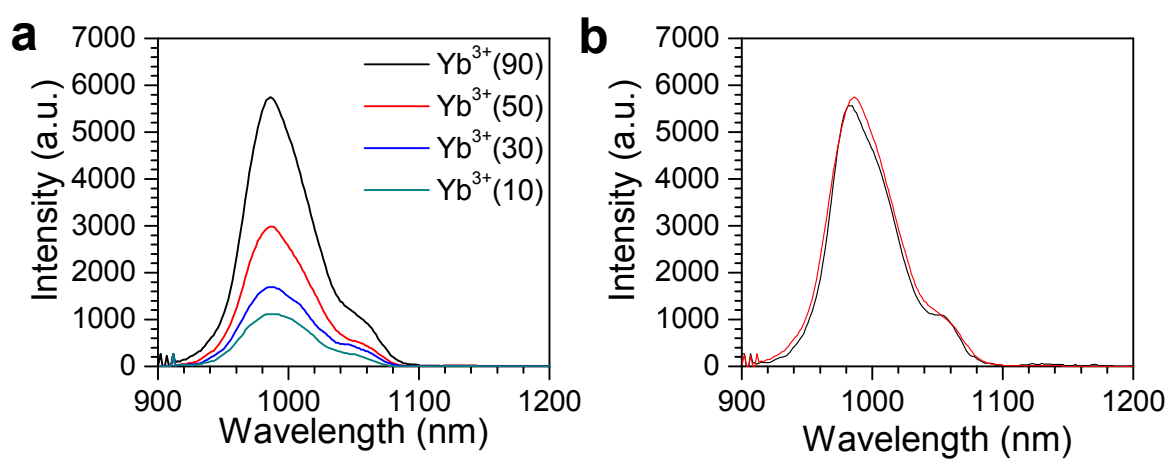

Figure S7. a) Down-converted emission spectra of oleic acid capped DCNPs $\mathrm{NaYF}_{4}$ : $\mathrm{x} \% \mathrm{Yb}^{3+} @ \mathrm{NaNdF}_{4}: \mathrm{Yb}^{3+}\left(\mathrm{X}=10,30,50\right.$ and 90\%) in cyclohexane. b) $\mathrm{NaYF}_{4}$ : 90\% $\mathrm{Yb}^{3+} @ \mathrm{NaNdF}_{4}: \mathrm{Yb}^{3+} \mathrm{DCNPs}$ before (red line) and after (black line) coated with mesoporous silica layer in water using $808 \mathrm{~nm}$ laser excitation at $2 \mathrm{~W}$.

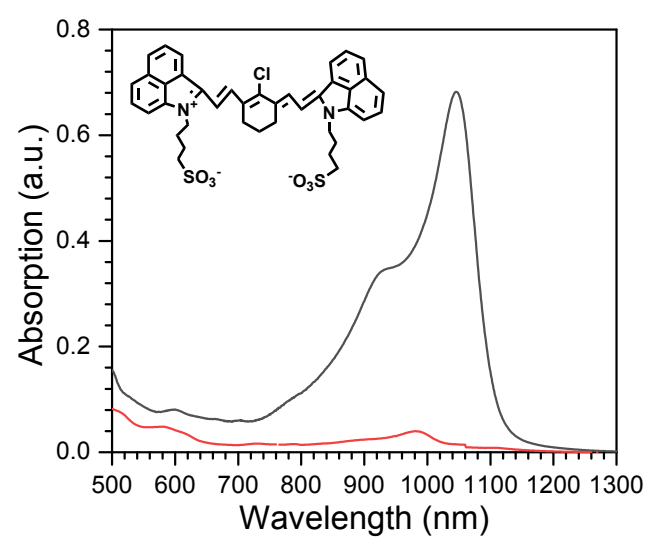

Figure S8. The absorption spectral of the dye FD1080 before (black line) and after (red line) additions of hypochlorite with the concentrations of $1 \times 10^{-3} \mathrm{M}$. 

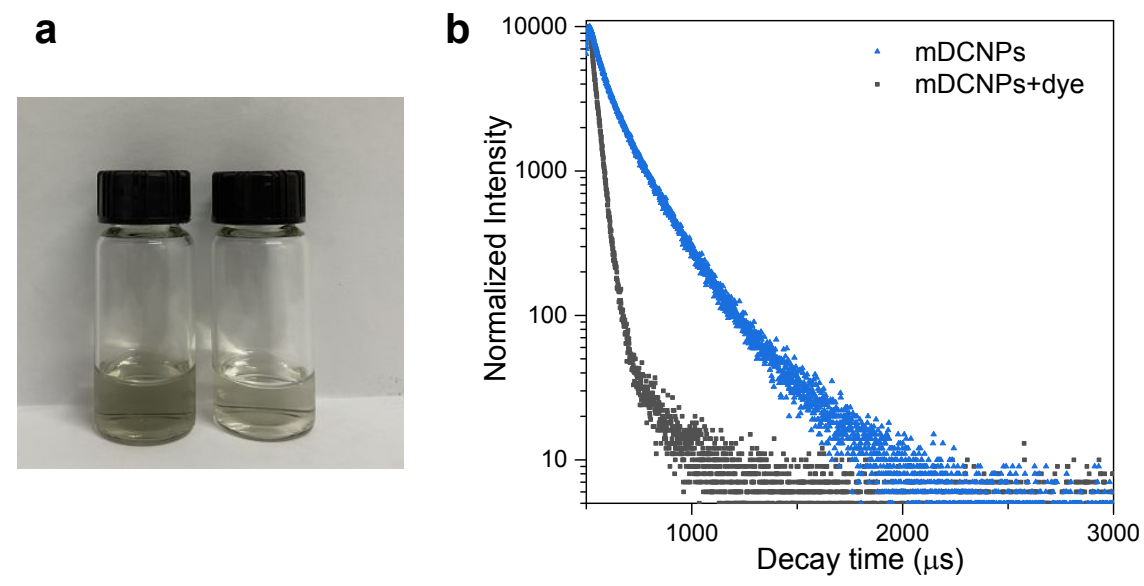

Figure S9. a) Photos of FD1080 before (left) and after (right) reacting with hypochlorite under natural light. b) Luminescence decay curves of $\mathrm{Yb}$ ions at $980 \mathrm{~nm}$ before (blue) and after (black) absorption of FD1080 $(80 \mu \mathrm{M})$.
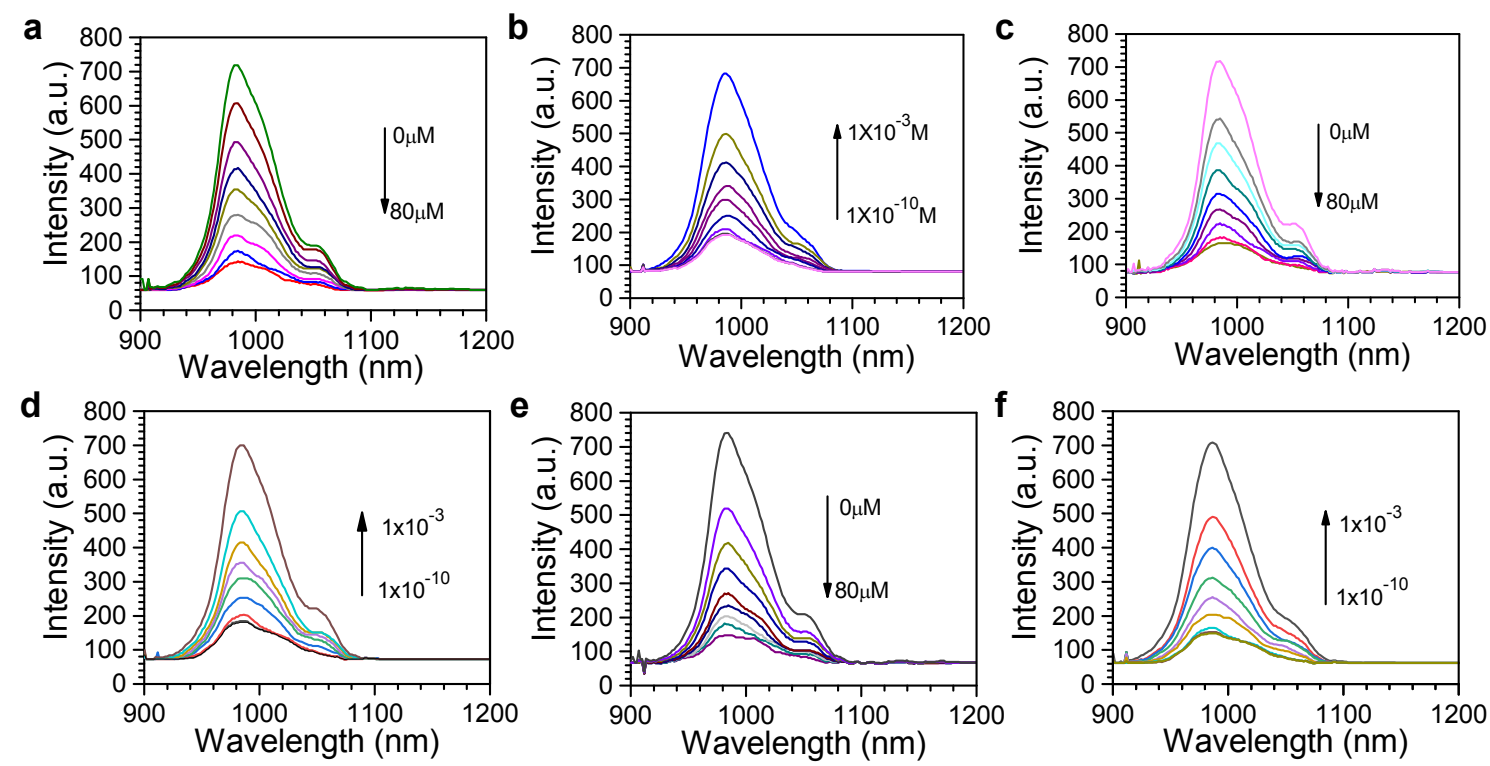

Figure S10. The luminescence quenching behaviors of a) $\mathrm{NaYF}_{4}: 10 \% \mathrm{Yb}^{3+} @ \mathrm{NaNdF}_{4}: \mathrm{Yb}^{3+}$, c) $\mathrm{NaYF}_{4}: 30 \% \mathrm{Yb}^{3+} @ \mathrm{NaNdF}_{4}: \mathrm{Yb}^{3+}$, e) $\mathrm{NaYF}_{4}: 50 \% \mathrm{Yb}^{3+} @ \mathrm{NaNdF}_{4}: \mathrm{Yb}^{3+}$ nanoparticles upon the addition of different amounts of FD1080. From top to bottom, the concentrations of the dye are $0,10,20,30,40,50,60,70$ and $80 \mu \mathrm{M}$. The luminescence recovery of $\mathrm{b}$ ) $\mathrm{NaYF}_{4}: 10 \% \mathrm{Yb}^{3+} @ \mathrm{NaNdF}_{4}: \mathrm{Yb}^{3+}$, d) $\mathrm{NaYF}_{4}: 30 \% \mathrm{Yb}^{3+} @ \mathrm{NaNdF}_{4}: \mathrm{Yb}^{3+}$, f) $\mathrm{NaYF}_{4}: 50 \% \mathrm{Yb}^{3+}$ (a) $\mathrm{NaNdF}_{4}: \mathrm{Yb}^{3+}$ nanoparticle upon the addition of different concentrations of hypochlorite. From bottom to top, the concentrations are $0,1 \times 10^{-10}, 1 \times 10^{-9}, 1 \times 10^{-8}, 1 \times 10^{-7}, 1 \times 10^{-6}, 1 \times 10^{-5}$, $1 \times 10^{-4}$ and $1 \times 10^{-3} \mathrm{M}$, respectively. 

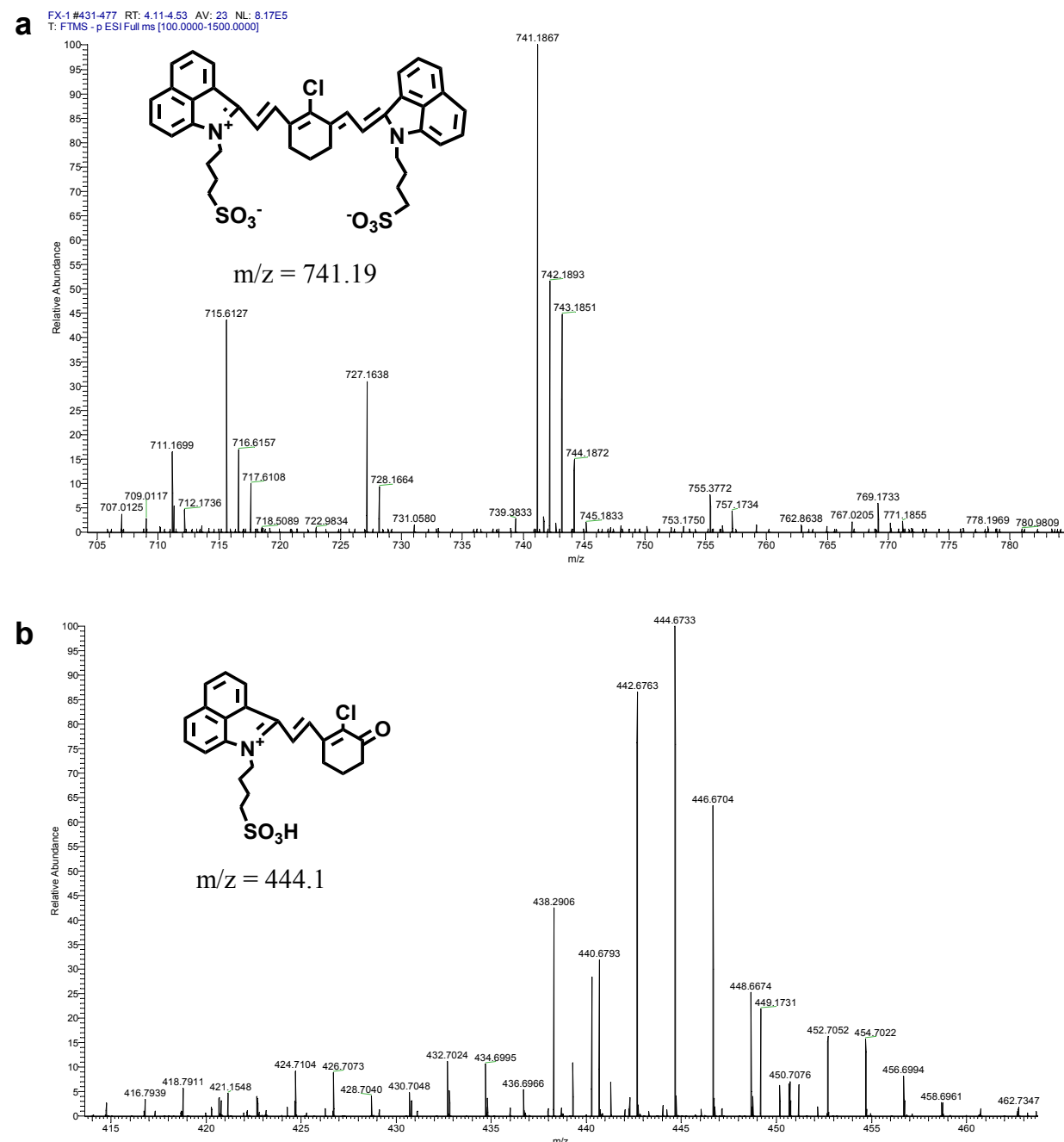

Figure S11. Mass spectra of FD1080 molecules before (a) and after (b) reacting with hypochlorite. 

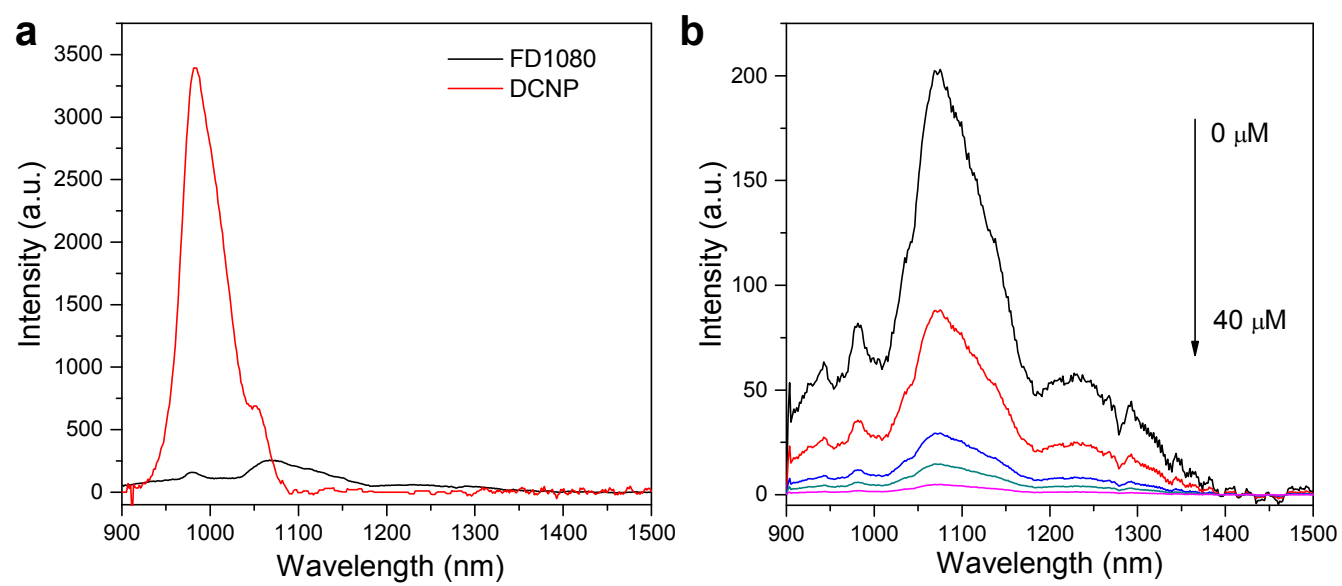

Figure S12. a) Down-convert emission spectra of the mDCNPs and FD1080 in DMSO under $808 \mathrm{~nm}$ excitation. b) The luminescence quenching of FD1080 after additions of different amounts of hypochlorite. From top to bottom, the concentration is $0,10,20,30$ and $40 \mu \mathrm{M}$.

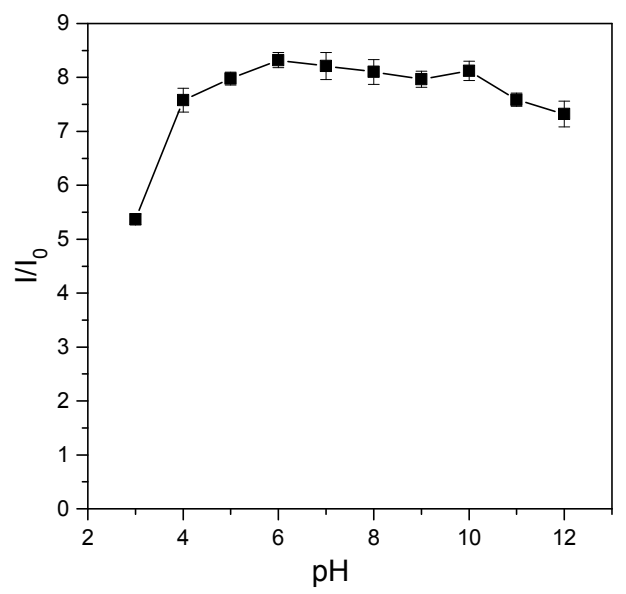

Figure S13. The influence of $\mathrm{pH}$ values on the luminescence enhancement of the nanoprobe, where $\mathrm{I}_{0}$ and I respectively represent the luminescence intensity of the nanoprobe before and after additions of $1 \mathrm{mM}$ of hypochlorite. 


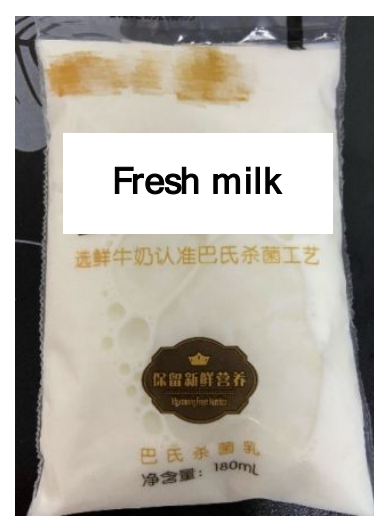

Figure S14. Raw milk samples for hypochlorite detection.

Table S1. An overview of recent literatures of hypochlorite detections.

\begin{tabular}{|c|c|c|c|}
\hline Materials & Linearity $(\mu \mathrm{M})$ & LOD $(\mu \mathrm{M})$ & Ref. \\
\hline $\begin{array}{l}\text { Cyanine 1-(Furan-2-yl)-N-(pyridin-2- } \\
\text { ylmethyl)-methanamine (CY-FPA) }\end{array}$ & $0-24$ & 0.70 & 1 \\
\hline $\begin{array}{c}\text { Carbondot/ Curcumin@ZIF-8 } \\
\text { (CD/CCM@@ZIF-8) }\end{array}$ & $0.1-50$ & 0.067 & 2 \\
\hline BODIPY-based fluorescent probe & $1-10$ & 0.0237 & 3 \\
\hline $\begin{array}{l}\text { lysosome-targetable fluorescent probe } \\
\text { (Lyso-naphthalimide-SeO) }\end{array}$ & $0-10$ & 0.0185 & 4 \\
\hline $\begin{array}{c}\text { Mitochondria two-photon fluorescent } \\
\text { probe (MITO-TP) }\end{array}$ & $0-80$ & 0.02 & 5 \\
\hline $\begin{array}{l}\text { Reversible fluorescent probe } \\
\text { (naphthalimide-Se) }\end{array}$ & $0-16$ & 0.586 & 6 \\
\hline Annulated BODIPY chalcogenide & $3.3-63.3$ & 3.7 & 7 \\
\hline mDCNPs-FD1080 & $1 \times 10^{-4}-9 \times 10^{-4}$ & $0.295 \times 10^{-4}$ & This work \\
\hline
\end{tabular}

\section{References:}

(1) Sun, M. T.; Yu, H.; Zhu, H. J.; Ma, F.; Zhang, S.; Huang, D. J.; Wang, S. H. Anal. Chem. 2014, 86, 671-677.

(2) Tan, H. L.; Wu, X. Y.; Weng, Y. H.; Lu, Y. J.; Huang, Z. Z. Anal. Chem. 2020, 92, 3447-3454.

(3) Liu, S. R.; Vedamalai, M.; Wu, S. P. Anal. Chim. Acta. 2013, 800, 71-76.

(4) Qu, Z. J.; Ding, J. X.; Zhao, M. Y.; Li, P. J. Photoch. Photobio. A. 2015, 299, 1-8.

(5) Yuan, L.; Wang, L.; Agrawalla, B. K.; Park, S. J.; Zhu, H.; Sivaraman, B.; Peng, J. J.; Xu, Q. H.; Chang, Y.

T. J. Am. Chem. Soc. 2015, 137, 5930-5938.

(6) Lou, Z. R.; Li, P.; Pan, Q.; Han, K. L. Chem. Commun. 2013, 49, 2445-2447.

(7) Manjare, S. T.; Kim, J.; Lee, Y.; Churchill, D. G. Org. Lett. 2014, 16, 520-523. 